\title{
Decreasing Salt in Hospital Meals Reduced Energy Intake in Elderly Japanese Inpatients
}

\author{
Keiko Hirose $^{1,2}$, Thao Phuong Tran ${ }^{1,2, *}$ and Shigeru YAMAmoto ${ }^{2}$ \\ ${ }^{1}$ Nutrition Department, Nerima Hikarigaoka Hospital, Nerima, Tokyo 179-0072, Japan \\ ${ }^{2} J u m o n j i$ University, Niiza, Saitama 352-8510, Japan
}

(Received September 17, 2020)

\begin{abstract}
Summary Japanese salt consumption is high, about $10 \mathrm{~g}$ salt/d. Low salt intake reduces the risk of hypertension and cardiovascular disease. However, saltiness is an important taste in daily meals, greatly influencing eating habits. When hospital admission is shortterm, reducing salt supply may have an adverse effect on food intake. The aim of this study is to find the effect of sudden change in dietary salt content on energy intake in elderly Japanese inpatients. The study is an observational study of 83 patients and was conducted in a hospital in Tokyo, Japan. The research period was three weeks, and included $8 \mathrm{~g}$ salt/d meals for the 1 st week, $7 \mathrm{~g}$ salt $/ \mathrm{d}$ meals for the $2 \mathrm{nd}$ week, and $7 \mathrm{~g}$ salt $/ \mathrm{d}$ meals with total $1 \mathrm{~g} / \mathrm{d}$ salt packs that patients were allowed to use freely for the 3rd week. The energy supply satisfied the individuals' energy requirements and was the same throughout the three weeks. Nutrition surveys and blood pressure measurements during the three weeks were conducted by dietitians and nurses, respectively. The results showed that energy intake of patients was reduced by about $90 \mathrm{kcal} / \mathrm{d}$ in the 2 nd week compared with the 1 st week and increased about $130 \mathrm{kcal} / \mathrm{d}$ in the $3 \mathrm{rd}$ week compared with the 2 nd week. Blood pressure did not change during the research period. When high salt intake has become a habit, reducing salt supply suddenly in a short time period may lead to decreased energy intake in elderly inpatients but does not affect blood pressure.
\end{abstract}

Key Words salt, hospital, Japan, DRI, elderly, nutrition status, nutrition intake

Sodium is an essential macronutrient. Within the body, sodium regulates extracellular fluid volume, maintains acid/base balance, neural transmission, renal function, cardiac output and myocytic contraction. Sodium chloride $(\mathrm{NaCl})$ is the prototypical stimulus for a salty taste. Saltiness is one of five tastes which are sensed by the tongue.

According to a systematic analysis in 2013, Japan ranked 15th in the world in daily salt consumption in 2010 at $12.4 \mathrm{~g}$ (1). A cross-sectional, epidemiologic study of 4,680 individuals ages 40 to $59 \mathrm{y}$ in Japan showed that 340 foods contributed more than $1 \mathrm{mg} /$ person/d sodium. Important dietary sources were soy sauce $(20 \%)$; soups $(16.4 \%)$, particularly miso soups (9.7\%); salted fish, seafood, fish roe (15\%); pickled vegetables and pickled plums (9.8\%), 9.5\% came from salt added to foods during home cooking and at the table, and from salt in fast foods and foods eaten at restaurants (2). According to the National Health and Nutrition Survey 2018, average salt intake of the Japanese population is about $10 \mathrm{~g} / \mathrm{d}$, males $11 \mathrm{~g}$ and females $9.3 \mathrm{~g}$; in particular, the elderly have the highest consumption (3). However, salt over-intake is known to increase the risk of hypertension and cardiovascular disease (4).

There have been some campaigns for a reduction in

\footnotetext{
*To whom correspondence should be addressed.

E-mail: tpthao95@gmail.com
}

salt intake and prevention of prehypertension/hypertension in the Japanese population but it is necessary to take a long-term approach. The WHO has recommended that adults consume less than $5 \mathrm{~g}$ salt/d. The Japanese dietary reference intake (DRI)-2015 recommended a salt intake of less than $8 \mathrm{~g} / \mathrm{d}$ for elderly males and $7 \mathrm{~g} / \mathrm{d}$ for elderly females (5). Many Japanese hospitals had served normal patients' meals with about $8 \mathrm{~g} / \mathrm{d}$ salt because Japanese elderly consumed high salt (about $10 \mathrm{~g} / \mathrm{d}$ ) at that time (3). Salt reduction is a difficult process and the Japanese recommendations envision reducing salt intake gradually every five years. Therefore, the Japanese DRI-2020 recommends less than $7.5 \mathrm{~g}$ salt/d for elderly males and $6.5 \mathrm{~g}$ salt/d for elderly females (6). The hospital's nutrition department decided to change salt supply to about $7 \mathrm{~g} / \mathrm{d}$ for patients, or by less than about $1 \mathrm{~g} / \mathrm{d}$ compared with before. These are recommendations but in fact the Japanese have only reduced intake gradually by about $0.08 \mathrm{~g}$ salt/y (7); it would be a major change in salt supply if hospital diets also change to follow the updated DRI.

Elderly inpatients have a high risk of malnutrition and there are many factors that can lead to reduced energy intake in elderly inpatients, such as disease, the side effects of medication, aging, cognitive problems, and dehydration (8). Therefore, it is a challenge for dietitians to balance patients' eating habits with satisfying the changing DRI for salt. Especially when the stay of elderly patients in the hosptial is short, changing eat- 


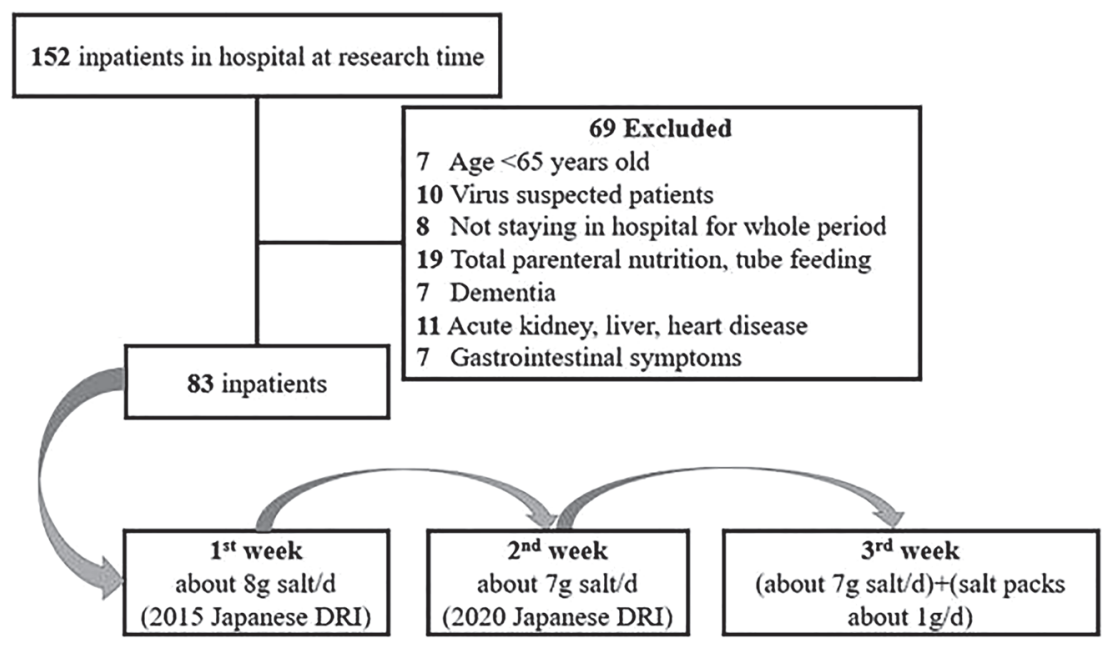

Fig. 1. Cohort flow diagram of study participants.

ing habits is not easy. When patients can eat well orally and their condition has been stabilized, it is time to discharge them. Therefore, we wondered whether it was really necessary to reduce the salt supply in hospital meals for normal elderly patients.

We hypothesized that salt intake may have an effect on the energy intake of elderly patients. Therefore, the aim of this study was to determine the effect of suddenly changing dietary salt content on energy intake in elderly Japanese patients.

\section{MATERIALS AND METHODS}

Settings and sample. The study was designed as an observational study and conducted from March to April 2020. The study site was Nerima Hikarigaoka Hospital, which is a hospital belonging to the Japan Association for the Development of Community Medicine (JADECOM), with 342 beds located in Nerima Ward, Tokyo. The data of this research was collected based on the retrospective medical record. We think that the changes in salt supply in this research depended on updated recommendation and treatment so the consent forms of subjects may not necessary in this research.

Subjects who met the inclusion criteria were recruited for the study: elderly patients with oral intake whose hospital stay lasted the entire research period and were not suffering from suspected virus, dementia, acute kidney conditions, heart disease, liver disease or gastrointestinal symptoms and were not receiving enteral, parenteral nutrition or an increased dose of hypertension medicine during the research period.

There were 83 subjects who were recruited according to the inclusion criteria from the medical records of 152 subjects during the research period (Fig. 1).

The research process took three weeks. The nutrition supply for each individual was the same for the 3 weeks and was calculated to satisfy nutrition requirements. In the 1 st week, patients consumed about $8 \mathrm{~g}$ salt/d (DRI2015 ) meals. In the 2 nd week, about $7 \mathrm{~g}$ salt/d (DRI2020) meals were consumed. Finally, in the 3rd week, besides about $7 \mathrm{~g}$ salt/d meals, salt packs, soy sauce packs and salt sprinkle packs with total about $1 \mathrm{~g}$ salt/d were added (patients could adjust the taste themselves).

Data collection. Characteristics, eating assistance levels, blood pressure, malnutrition status and oral intake data for 83 patients were collected.

Malnutrition was assessed using the criteria of the Global Leadership Initiative on Malnutrition (GLIM) definition, which is based on phenotypic criteria including change in body weight, low BMI, and reduced muscle mass, as well as etiologic criteria including reduced food intake or assimilation, and disease burden. The GLIM definition includes 2 steps. First, a validated nutritional risk screening tool is used to identify individuals at risk of malnutrition; in this study we used the Mini Nutritional Assessment-Short Form (MNA-SF). Second, for people at risk of malnutrition, malnutrition is defined by the detection of at least 1 phenotypic and 1 etiologic criterion (9).

Eating assistance levels were recorded with 3 levels: independent, partially assisted and fully assisted. The independent level meant that patients were able to eat without any assistance. The partially assisted level meant that patients received partial support from medical staff such as holding a patient's hand to help them guide food to their mouth. The fully assisted level meant that the medical staff fed the patient with complete support.

A one-week menu cycle was developed by hospital nutrition software (HOPE/EGMAINGX food supply library-Fujitsu Limited, Japan). The nutrition supply followed nutrition requirements for each individual. Nutrition requirements were calculated for individual patients by dietitians with approximately 10 years' experience. Then after the food was prepared, we used a digital salt meter (Atago ES-421, Japan) to check randomly one meal a day to ensure that chefs were following the menus. Nutrition intake data were collected by nurses and calculated by dietitians. In our hospital, checking residual food from patients' meals is a part of nurses' duties and this nutrition intake information is recorded in electronic medical records. For example, 
Table 1. Patients' characteristics $(n=83)$.

\begin{tabular}{|c|c|c|c|c|}
\hline Variable & $\begin{array}{l}\text { Overall } \\
(n=83)\end{array}$ & $\begin{array}{c}\text { Male } \\
(n=40)\end{array}$ & $\begin{array}{l}\text { Female } \\
(n=43)\end{array}$ & $p$-value \\
\hline Age, y $($ mean $\pm S D)$ & $80.1 \pm 9.0$ & $77.6 \pm 9.0$ & $82.4 \pm 8.4$ & $<0.05^{1}$ \\
\hline \multicolumn{5}{|l|}{ Main diseases, $n(\%)$} \\
\hline Cancer & $15(18.1)$ & $13(32.5)$ & $2(4.7)$ & \\
\hline Neurological disease & $19(22.9)$ & $10(25.0)$ & $9(20.9)$ & \\
\hline Broken bone & $12(14.4)$ & $3(7.5)$ & $9(20.9)$ & \\
\hline Immune system disease & $11(13.3)$ & $3(7.5)$ & $8(18.6)$ & \\
\hline Other (e.g. diabetes, lipid disorder) & $26(31.3)$ & $11(27.5)$ & $15(34.9)$ & \\
\hline Hypertension rate, $n(\%)$ & $54(65.1)$ & $25(62.5)$ & $29(67.5)$ & \\
\hline \multicolumn{5}{|l|}{ Eating assistance levels, $n(\%)$} \\
\hline Independent & $28(33.7)$ & $21(52.5)$ & $7(16.3)$ & \\
\hline Partially assisted & $28(33.7)$ & $12(30)$ & $16(37.2)$ & \\
\hline Fully assisted & $27(32.6)$ & $7(17.5)$ & $20(46.5)$ & \\
\hline $\mathrm{BMI}\left(\mathrm{kg} / \mathrm{m}^{2}\right)($ mean $\pm \mathrm{SD})$ & $21.0 \pm 4.2$ & $21.2 \pm 4.2$ & $20.8 \pm 4.2$ & $>0.05^{1}$ \\
\hline Malnutrition, $n(\%)$ & $51(61.5)$ & $27(67.5)$ & $24(55.8)$ & $>0.05^{2}$ \\
\hline
\end{tabular}

${ }^{1}$ Unpaired Student's t-test, ${ }^{2}$ Chi square test.

how much rice/porridge and how much of the main dish patients ate. Based on these records, the other medical staff members, especially dietitians, can adjust diets for patients when necessary. The data were calculated by dietitians as an average for three non-consecutive days of each week and for the three weeks of the whole research period.

Systolic blood pressure (SBP) and diastolic blood pressure (DBP) data were collected in the morning at the end of each week by nurses.

Statistical analysis. All statistical analyses were performed using the Stata version 12.0 software. Qualitative variables were expressed as the number of malnutrition subjects (percentage), and quantitative variables, including parametric and nonparametric values evaluated by the histogram, were expressed as mean \pm standard deviation (SD) such as age. Comparisons between groups were made by using the Chi square test for qualitative variables, unpaired Student's $t$-test for quantitative variables. Comparisons in the same group for the three periods were made using ANOVA with post-hoc Tukey HSD test. $p$-values of less than 0.05 were considered statistically significant for all the analyses.

\section{RESULTS}

Table 1 indicates the characteristics of subjects. Proportion of males was $48 \%(40 / 83)$. Mean age of subjects was about $80 \mathrm{y}$ old, and females $(82.4 \pm 8.4 \mathrm{y}$ old $)$ were older than males $(77.6 \pm 9.0$ y old $)$ with $p<0.05$. Some main disease which patients suffered were cancer $(18.1 \%)$, neurological disease $(22.9 \%)$, broken bone (14.4\%), immune system disease $(13.3 \%)$ and other (31.3\%). Besides, there were about $65.1 \%$ of hypertension patients. Eating assistance levels of subjects

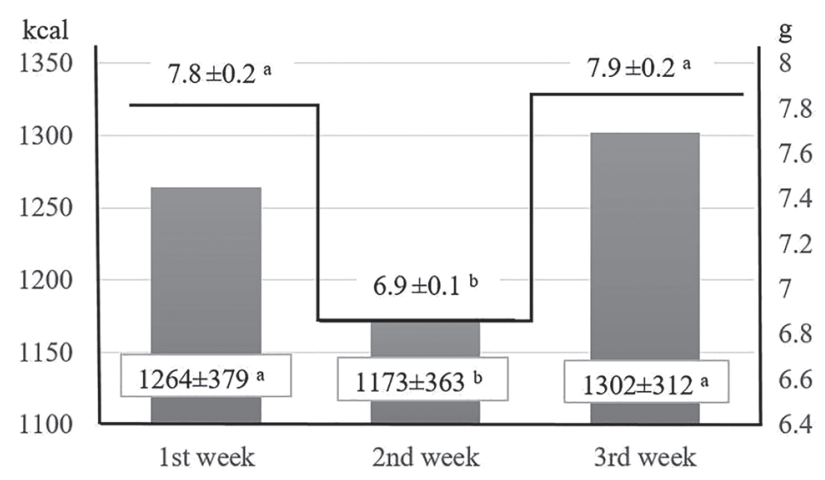

Fig. 2. Salt supply and energy intake at the 1st, 2nd and 3rd week $(n=83)$. Data are mean \pm SD. ANOVA with post-hoc Tukey HSD test was used. Different letters above the data indicate significantly different means $(p<0.05)$.

included independent $(33.7 \%)$, partially assisted (33.7\%) and fully assisted levels (32.6\%). About half of males $(52.5 \%)$ had the ability to be independent and about half of females (46.5\%) required full assistance in eating. Mean BMI of subjects was $21 \mathrm{~kg} / \mathrm{m}^{2}$. According to GLIM criteria, there was $61.5 \%(51 / 83)$ of subjects who suffered from malnutrition. There was no difference between the male and the female group in BMI indicators and malnutrition rates.

Figure 2 shows the salt supply and energy intake at the 1st, 2nd and 3rd week. Although energy supply for the three weeks was the same, we found lower energy intake for the 2nd week compared with that of the other weeks. Salt supply for the 1st week and the 3rd week did not differ, but the 2nd week was lower than the 1 st week by about $1 \mathrm{~g}$ salt/d. Energy intake for the 
Table 2. Eating assistance levels and energy intake at the 1st, $2 \mathrm{nd}$ and $3 \mathrm{rd}$ week.

\begin{tabular}{lccc}
\hline Eating assistance levels & 1st week & 2nd week & 3rd week \\
\hline Independent & $1,503 \pm 320^{\mathrm{a}}$ & $1,371 \pm 288^{\mathrm{b}}$ & $1,492 \pm 174^{\mathrm{a}}$ \\
Partially assisted & $1,257 \pm 356^{\mathrm{a}}$ & $1,159 \pm 332^{\mathrm{b}}$ & $1,294 \pm 292^{\mathrm{a}}$ \\
All assisted & $1,023 \pm 305^{\mathrm{a}}$ & $984 \pm 368^{\mathrm{a}}$ & $1,114 \pm 333^{\mathrm{a}}$ \\
\hline
\end{tabular}

a,b ANOVA with post-hoc Tukey HSD test was used. In each line, different letters above the data indicate significantly different means $(p<0.05)$.

Table 3. Blood pressure at the 1st, 2nd and 3rd week $(n=83)$.

\begin{tabular}{lrrc}
\hline Variable & 1st week & 2nd week & 3rd week \\
\hline SBP $(\mathrm{mmHg})$ & $126 \pm 14^{\mathrm{a}}$ & $124 \pm 17^{\mathrm{a}}$ & $125 \pm 11^{\mathrm{a}}$ \\
$\mathrm{DBP}(\mathrm{mmHg})$ & $72 \pm 13^{\mathrm{a}}$ & $72 \pm 11^{\mathrm{a}}$ & $71 \pm 9^{\mathrm{a}}$ \\
\hline
\end{tabular}

Data are mean \pm SD. ANOVA with post-hoc Tukey HSD test was used. In each line, different letters above the data indicate significantly different means $(p<0.05)$.

2nd week was lower than that of the 1st week by about $90 \mathrm{kcal} / \mathrm{d}$. Energy intake in the 3rd week was higher than that of the 2 nd week by about $130 \mathrm{kcal} / \mathrm{d}$.

Table 2 shows the eating assistance levels and energy intake at the 1st, 2nd and 3rd week. The independent, partially assisted and fully assisted groups had energy intake about $1,500 \mathrm{kcal} / \mathrm{d}, 1,260 \mathrm{kcal} / \mathrm{d}$ and 1,020 $\mathrm{kcal} / \mathrm{d}$ at $1 \mathrm{st}$ week, respectively. When reducing by about $1 \mathrm{~g}$ salt/d, we observed an energy reduction of about $130 \mathrm{kcal} / \mathrm{d}$ in the independent group and about $100 \mathrm{kcal} / \mathrm{d}$ in the partially assisted group $(p<0.05)$. In the 3rd week, by adding more salt packs, soy sauce packs and salt sprinkle packs with a total about $1 \mathrm{~g}$ salt/d besides dishes, the salt supply was the same as the 1st week, the energy intake also returned to the same as the 1st week. In the fully assisted group, energy intake did not change over the 3 weeks.

Table 3 shows blood pressure at the 1st, 2nd and 3rd week. Blood pressure did not change during the research period.

\section{DISCUSSION}

When patients are admitted to the hospital for a short time, the taste of food, especially saltiness, may play an important role. If the saltiness is very different from what they are used to, it is not easy for them to enjoy hospital meals. In addition, the effect on hormone regulation of electrolytes and osmotic pressure balance is also important (10). If salt is changed suddenly, the excreting hormones cannot response well, which leads to disordered electrolytes and reduced appetite. The elderly also have a high risk of suffering from dehydration and hidden dehydration (11). In order to adjust electrolyte balance, not only medicine but also meals are essential. Therefore, supplying a suitable salt amount for an individual will be based on many factors and needs to be considered carefully by doctors and dietitians.

Decreasing salt intake in the population will lower blood pressure and reduce cardiovascular disease (12). However, a systematic review showed that intensive interventions, unsuited to primary care or population prevention programs, provide only small reductions in blood pressure and sodium excretion, and the effects on deaths and cardiovascular events are unclear (13). In this study, we did not find a difference in subjects' blood pressure when patients consumed less salt for a short time. With hypertensive elderly patients admitted to the hospital for other reasons, maintaining their hypertension medicine dose to control blood pressure may be easier for doctors to treat patients than suddenly reducing salt in meals, which leads to reduced appetite in patients. A research study has shown that subjects who took hypertension medication consumed significantly more salt than those who had no hypertension (14). Therefore, with normal elderly patients it may not be really necessary to serve hospital meals with very low salt supply compared with patients' habit.

In addition, the results of the study showed that the amount of salt supply in the 2nd week was less than the 1 st week by about $1 \mathrm{~g}$ day and that energy intake was reduced about $90 \mathrm{kcal} / \mathrm{d}$ although the energy supply was not different. The dietitian's solution was to add salt, soy sauce, or a sprinkled rice pack containing about $1 \mathrm{~g} / \mathrm{d}$ salt beside patients' dishes to put in soup, main dishes and rice according to the patients' choice during the 3rd week. The results indicated that the energy intake of patients in the 3rd week increased by $130 \mathrm{kcal} / \mathrm{d}$ compared with the 2 nd week although the energy supply was the same. Elderly Japanese patients have a high proportion of malnutrition, about $60 \%$ in this study. This change may improve patients' oral intake and nutritional status.

In this study, we observed a difference in energy intakes depending on eating assistance levels. The independent and partially assisted groups reduced energy intake when salt intake decreased about $1 \mathrm{~g} / \mathrm{d}$ in 2 nd week. But the fully assisted group did not reduce energy intake significantly. The fully assisted group had an energy intake that was quite low, about 1,000 kcal; this may be just enough for basic metabolic energy for the body to maintain life. In addition, their ability to choose foods also would be limited. It may be reason why this group did not change energy intake very much in the 2nd week.

Reducing salt in patients' meals to follow DRI and to 
still suit patients' eating habits is always a challenge for hospital dietitians. Japanese food culture is famous for Washoku, which may be a valuable tool in supporting healthy eating (15). A previous report showed that reducing the consumption of miso soup and Japanese pickles may be an effective approach for decreasing the level of salt intake in the general Japanese population (16). The use of flavors that have no salty taste but enhance the saltiness of foods when used together with salt can also reduce the amount of salt to be added. Soy sauce has a distinct taste called umami, which was shown to increase perceived saltiness (17).

The above research was conducted under research conditions on healthy people but in practice, it is still often difficult to apply this knowledge and to have a noticeable effect on reducing the salt intake of hospitalized elderly patients with salty eating habits that have been established over a long period of time. A research study has shown that the most pronounced increase in elderly people's detection threshold has been observed for sour and bitter tastes, but their perception of salty, sweet, and umami tastes also seems to decline with age. It has often been suggested that elderly people who lose their sense of taste may eat less food or choose stronger flavors with a greater consumption of sweet and salty foods (18). The main point of this study was a sudden reduction in salt supply of about more than 10\%/wk and this led to decreased energy intake. Another study on healthy Australians about gradually reducing salt in bread by about $5 \% / \mathrm{wk}$ had the effect of reducing the salt content in the bread by about one-quarter over $6 \mathrm{wk}$ while maintaining consumer acceptance (19).

The role of the dietitian is trying to balance taste, DRI and energy intake to provide the best nutrition treatment for patients. We think that the dietitian can achieve proper dietary management more easily if the salt DRI for the elderly is within a larger range. Hospital meals need to be served for many patients and the number of patients is not stable. Therefore, satisfying individual eating preferences is difficult when each person has his or her own eating habits. Letting patients choose a suitable salty taste for themselves within a limited range may increase elderly patients' energy intake. In addition, the role of a dietitian who is responsible for a ward is to know the eating situation of all patients every day. Through this study, reducing salt had an effect on dietary intake of almost all patients and especially on patients who can eat independently and usually receive less care from the dietitian. With timely intervention by the dietitian, patients will have better nutrition care and will recover sooner in the hospital.

We believe that our understanding is correct, although the study was conducted in a hospital so that the role of medical care could not be ignored. During the research period, subjects who had medical treatment that had a major effect on their energy intake were excluded in order to confirm the changes in salt supply as a main factor in the energy intake of subjects. The other limitation in this study is the information about salt consumption of patients before the study was lack. If we can conduct a control group, this study will be more interesting.

In conclusion, reducing salt supply suddenly may lead to decreased energy intake in elderly inpatients and not affect blood pressure.

\section{Authorship}

Research conception and design: TPT and KH; experiment: TPT and KH; statistical analysis of data: TPT and SY; interpretation of the data: TPT, KH and SY; writing of the manuscript: TPT.

\section{Disclosure of state of COI}

No conflicts of interest to be declared.

\section{Acknowledgments}

The authors would like to thank to Nerima Hikarigaoka Hospital and Jumonji University. The corresponding author would like to express gratitude to the Otsuka Toshimi Scholarship Foundation for financial support to study in a PhD program in Japan. Finally, we also would like to thank Andrew Durkin, Prof. Emeritus of Indiana University, for editing our English.

\section{REFERENCES}

1) Powles J, Fahimi S, Micha R, Khatibzadeh S, Shi P, Ezzati M, Engell RE, Lim SS, Danaei G, Mozaffarian D, Group (NutriCoDE) on behalf of the GB of DN and CDE. 2013. Global, regional and national sodium intakes in 1990 and 2010: a systematic analysis of $24 \mathrm{~h}$ urinary sodium excretion and dietary surveys worldwide. BMJ Open 3: e003733.

2) Anderson C, Appel L, Okuda N, Brown I, Chan Q, Zhao L, Ueshima H, Kesteloot H, Miura K, Curb J, Yoshita K, Elliott P, Yamamoto M, Stamler J. 2010. Dietary sources of sodium in China, Japan, the United Kingdom, and the United States, women and men aged 40 to 59 years: The INTERMAP study. J Am Diet Assoc 110: 736-745.

3) Ministry of Health, Labour and Welfare. 2018. National Health and Nutrition Survey-2018. Japan.

4) Hooper L, Bartlett C, Smith GD, Ebrahim S. 2004. Advice to reduce dietary salt for prevention of cardiovascular disease. Cochrane Database of Systematic Reviews 2004: CD003656.

5) Ministry of Health, Labour and Welfare. 2015. Dietary Reference Intake for Japanese.

6) Ministry of Health, Labour and Welfare. 2020. Dietary Reference Intake for Japanese.

7) Otsuka R, Kato Y, Imai T, Ando F, Shimokata H. 2011. Decreased salt intake in Japanese men aged 40 to 70 years and women aged 70 to 79 years: An 8-year longitudinal study. J Am Diet Assoc 111: 844-850.

8) Amarya S, Singh K, Sabharwal M. 2015. Changes during aging and their association with malnutrition. I Clin Gerontol Geriatr 6: 78-84.

9) Cederholm T, Jensen GL, Correia MITD, Gonzalez MC, Fukushima R, Higashiguchi T, Baptista G, Barazzoni R, Blaauw R, Coats AJS, Crivelli AN, Evans DC, Gramlich L, Fuchs-Tarlovsky V, Keller H, Llido L, Malone A, Mogensen KM, Morley JE, Muscaritoli M, Nyulasi I, Pirlich M, Pisprasert V, Schueren MAE, Siltharm S, Singer P, Tappenden K, Velasco N, Waitzberg D, Yamwong P, Yu J, Van Gossum A, Compher C, GLIM Core 
Leadership Committee, GLIM Working Group. 2019. GLIM criteria for the diagnosis of malnutrition-A consensus report from the global clinical nutrition community. J Cachexia Sarcopenia Muscle 10: 207-217.

10) Chen JS, Sabir S, Al Khalili Y. 2020. Physiology, osmoregulation and excretion. In: StatPearls. StatPearls Publishing, Treasure Island, FL.

11) Shimizu M, Kinoshita K, Hattori K, Ota Y, Kanai T, Kobayashi H, Tokuda Y. 2012. Physical signs of dehydration in the elderly. Intern Med J 51: 1207-1210.

12) He FJ, Li J, MacGregor GA. 2013. Effect of longer term modest salt reduction on blood pressure: Cochrane systematic review and meta-analysis of randomised trials. BMJ 346: f1325.

13) Hooper L, Bartlett C, Davey Smith G, Ebrahim S. 2002. Systematic review of long term effects of advice to reduce dietary salt in adults. BMJ 325: 628.

14) Toda A, Ishizaka Y, Tani M, Yamakado M. 2015. Current dietary salt intake of Japanese individuals assessed during health check-up. Hypertens Res 38: 163-168.
15) Gabriel AS, Ninomiya K, Uneyama H. 2018. The role of the Japanese traditional diet in healthy and sustainable dietary patterns around the world. Nutrients 10: 173.

16) Wakasugi M, Kazama JJ, Narita I. 2015. Associations between the intake of miso soup and Japanese pickles and the estimated 24-hour urinary sodium excretion: A population-based cross-sectional study. Intern Med J 54: 903-910.

17) Goh FXW, Itohiya $Y$, Shimojo R, Sato T, Hasegawa K, Leong LP. 2011. Using naturally brewed soy sauce to reduce salt in selected foods: salt reduction with soy sauce in foods. J Sens Stud 26: 429-435.

18) Sergi G, Bano G, Pizzato S, Veronese N, Manzato E. 2017. Taste loss in the elderly: Possible implications for dietary habits. Crit Rev Food Sci Nutr 57: 3684-3689.

19) Girgis S, Neal B, Prescott J, Prendergast J, Dumbrell S, Turner C, Woodward M. 2003. A one-quarter reduction in the salt content of bread can be made without detection. Eur J Clin Nutr 57: 616-620. 